\section{Voluntary forgetting of a shared memory load ${ }^{1}$}

ALAN E. GROSS, JOHN BARRESI, and EDWARD E. SMITH, University of Wisconsin, Madison, Wis. 53705

Seventy-three S-pairs were instructed to remember a list of words, half of which were valued 50 times more than the other half. In each S-pair, one $S$, the assigner, decided whether he or his partner was responsible for remembering each word. Later $S s$ were asked to recall (Experiment l) or recognize (Experiment 2) either their own or their partner's words. Assigners in the recall experiment forgot more low than high-valued words, and more of their partner's than their own words. No such effects were obtained in the recognition experiment. $A$ selective rehearsal explanation was offered for the assigner's selective forgetting.

Several recent studies suggest that $S$ can voluntarily forget or "drop" material from short-term memory, e.g., Bjork, LaBerge, \& Legrand, 1968; Glucksberg \& King, 1967; Weiner, 1966; Weiner \& Reed, 1969. For example, in the Weiner and Reed study on each trial $S$ saw a consonant trigram plus a color cue and then, after a brief intervening task, attempted to recall the trigram. One color indicated that $S$ should remember the trigram but not rehearse it during the intervening task, while another color indicated that $S$ should forget the trigram after seeing it but then attempt to recall it at the time of the memory test. Recall in the latter condition was poorer than recall in the former, supporting the notion of voluntary forgetting. One problem with Weiner's "instructional cue" methodology is that it involves giving $S$ ambiguous instructions-"forget, then recall." $2 \mathrm{~A}$ preferable alternative would be to give $S$ (or to have $S$ give himself) an unambiguous instruction that would induce him to forget selectively certain material that would later be tested. This can be accomplished by directing $S$ to give someone else part of his memory load. Such a procedure might allow $S$ to forget that part of his memory load that he decides to assign to someone else.

Instances of assigning part of one's memory load to another person abound in real-life situations, but we know of no experimental evidence which indicates that such assignment or delegation is an effective strategy for reducing memory load. In fact, it is possible that $S$ only forgets the material he assigns away when that material is unimportant. On the other hand, if the material in question is important, $\mathrm{S}$ may utilize the assignment strategy for a totally different purpose: to ensure that the material will be recalled by at least one person. In the latter case, assignment does not serve as an instruction to forget; on the contrary, it occurs when the $S$ is highly motivated to remember the material in question. Thus, we propose two distinct goals for sharing a memory load: the first involving selective forgetting in order to decrease memory load, the second involving utilizing independent storage systems in order to increase the probability of at least one person remembering a fixed memory load.

The purpose of the present study was to assess the effects of delegating part of a memory load when the material was either low or high in value. A recognition task, as well as a recall task, was employed to determine whether the results reflect pure storage effects (which should occur with both measures) or primarily rehearsal effects (which presumably are more operative in recall than in recognition, e.g., Eagle \& Leiter, 1964; Atkinson \& Wickens, 1969).

\section{GENERAL EXPERIMENTAL PLAN}

Pairs of Ss were instructed to remember a list of 36 words, half of which were valued 50 times as highly as the other half. Payoff was contingent on the number of words recalled or recognized by at least one $S$ and all money was to be divided equally between the $S$ pair. One $S$ was made responsible for assigning to-be-remembered words either to himself or to his partner.

\section{EXPERIMENT 1 (RECALL)}

Seventy-six high school students, 32 males and 44 females, were recruited from respondents to a Madison, Wisconsin, newspaper advertisement. At the start of the experiment, a female $E$ instructed two same-sex Ss that they were to work together as a team, each $S$ being responsible for remembering one word in each pair of a tape-recorded list of 18 word pairs. The Ss were given 75 cents prior to the task and were assured that they would earn enough additional money during the experiment to exceed the $\$ 1.50$ minimum promised in the advertisement. Then, a coin was tossed to determine which of the two Ss would assign words (assigner) and which would simply attempt to remember words assigned to him (assignee). Word value, either $1 / 2$ cent or 25 cents, was announced on the tape prior to each word, for example, "one-half, basket; twenty-five, table." Presentation time for this information (word pair plus values) was approximately $5 \mathrm{sec}$. For each word pair, the assigner was instructed to state aloud who was responsible for each word in the following format: e.g., "you take basket, I'll take table." Requiring the assigner to repeat both words ensured that he attended to all of the to-be-remembered material. The assigner had approximately $5 \mathrm{sec}$ to announce his decision before the next word pair was presented. A practice list of 10 pairs followed by a practice free recall test, in which each $S$ attempted to recall all of the words presented, was used to familiarize Ss with the procedure. The practice recall test was scored immediately and results were fed back to the Ss so that the importance of remembering high-valued words could be emphasized. Then the experimental list was presented.

The experimental list consisting of 18 high-frequency word pairs was selected from the $A$ or AA range of the Thorndike-Lorge word count (1944). The highest within-pair and between-pair associations were .001 and .036 , respectively (Palermo-Jenkins norms, 1964). Paired words contained an equal number of syllables. For five pairs, a high-valued (25 cents) word was followed by a low-valued ( $1 / 2$ cent) word; there were also five low-high pairs, four high-high pairs, and four low-low pairs. Approximately half of the Ss heard a second tape which was prepared such that words high valued on the first tape were low valued on the second, i.e., stimulus order was not changed. Word pairs were presented every $10 \mathrm{sec}$, preceded by a brief warning tone.

Immediately after presentation of the experimental list, Ss were asked to recall (in any order) either the assigner's $(\mathrm{N}=20)$ or the assignee's $(\mathrm{N}=18)$ words but not both. Thus, contrary to initial instructions, Ss were asked to recall only their own or only their partner's words; however, they were informed that they would be paid double for each word so that the procedural change would not affect potential earnings. ${ }^{3}$

\section{EXPERIMENT 2 \\ (RECOGNITION)}

Seventy high school students, 32 males and 38 females, recruited from the $S$ pool used for Experiment 1 participated. The procedure and materials were identical to those used in Experiment 1 except for modifications making it possible to test recognition. Because it was not known in advance which $S$ of the pair would be responsible for which words, it was necessary to prepare recognition tests tailored to each $S$ while the experiment was in progress. To accomplish this, E 

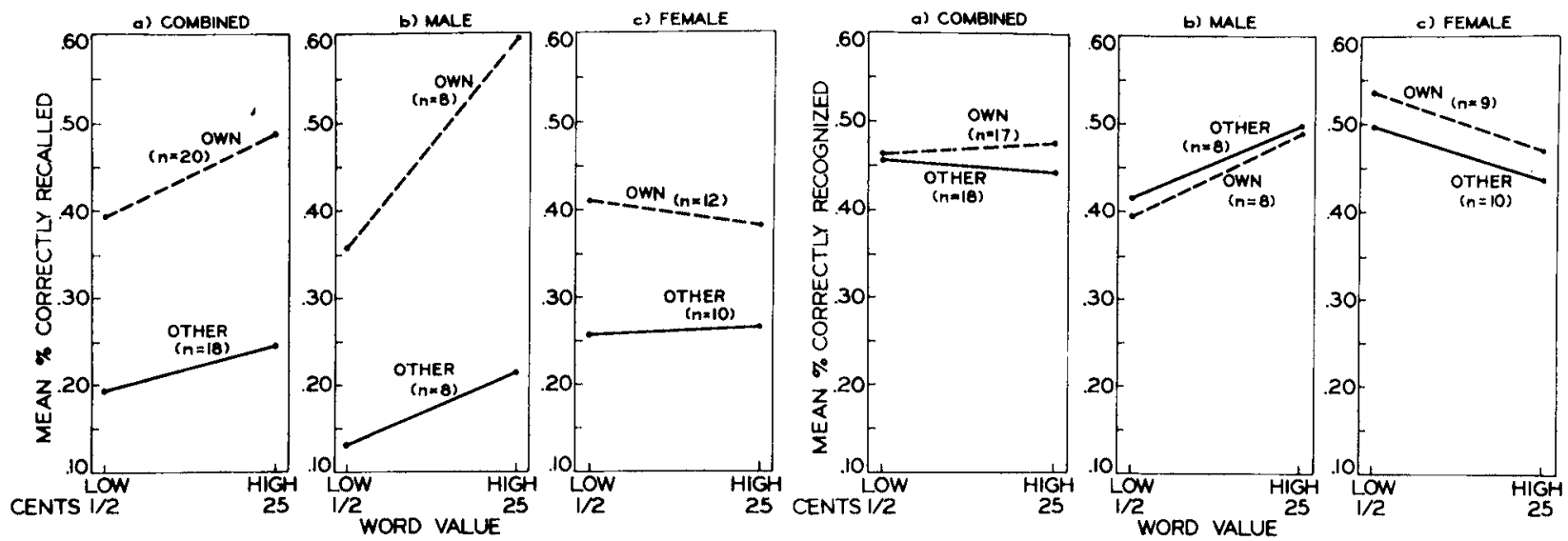

Fig. 1. Mean percentage correctly recalled as a function of word value, with assignment condition as the parameter for (a) combined Ss, (b) male Ss, and (c) female Ss.

Fig. 2. Mean percentage correctly recognized as a function of word value, with assignment condition as the paramoter for (a) combined Ss, (b) male Ss, and (c) female Ss.

prepared 36 stacks of index cards, one stack for each word on the experimental list. Each stack contained six cards-two copies of each of three words, the critical word on the experimental list and two recognition foils that were highly associated with the critical word. After hearing the assignment, $E$ handed the six-card stack containing the words to be recognized (in 17 cases the assigner's words, and in 18 cases the assignee's words), to an assistant and retained the stack containing the other words. ${ }^{4}$ The assistant then sorted the six cards into predetermined spaces on a large table. A barrier prevented $S$ from viewing $E$ and her assistant during the sorting process. In this manner, two identical recognition decks, one for each $S$, were prepared in a predetermined arder, critical words being randomly separated from their foils. The Ss were instructed to choose exactly 18 from the 54 choices in the deck. Again, Ss were tested only on their own or only on their partner's words.

\section{RESULTS}

Separate analyses were run for assigner and assignee roles. A mixed factorial analysis of variance was performed on arcsine transformations of proportions of words remembered (Winer, 1962, p. 221). Between-S factors were: own words or partner's words on the memory test (own-other); sex of the pair, and first or second tape; value, 25 cents or $1 / 2$ cent, was a within-S variable. 5

Recall scores (Experiment 1) for assigners are presented in Fig. 1a, and show that they recalled more of their own words than their partner's words $[F(1,30)=34.97, p<.001]$. Assigners also recalled more high than low-valued words $[F(1,30)=4.82, p<.05]$; however, this effect was totally due to males [interaction
$F(1,30)=6.28, p<.05$, see Fig. $1, b$ and c]. Males were also more sensitive to the own-other variable [interaction $F(1,30)=5.63, p<.05$, Fig. $1, b$ and $c] .6$ Recognition data (Experiment 2) for assigners is presented in Fig. 2. Neither value nor assignment (own-other) significantly affected recognition scores in Experiment 2. The hypothesized interaction between value and own-other for assigners was not supported in either experiment.

With respect to assignee performance, assignees recalled (Experiment 1) more of their own words than other words $[F(1,30)=12.25, p<.01]$ but no other variables affected assignee recall. There were no main effects for assignee recognition (Experiment 2); however, the Own-Other by Value and the Own-Other by Value by Sex interactions were significant at $p<.05$. These interactions indicate that assignees recognized more of their own low-valued words, but more of their partner's high-valued words, and that this relationship held only for males.

\section{DISCÜSSION}

The interaction between word value and assignment (own-other) for assigners received no support in either study; however, main effects for these two variables were obtained in the recall experiment, although they were largely limited to male assigners. The strength of these effects for male assigners in Experiment 1 (recall), compared with an almost complete absence of effects in Experiment 2 (recognition) is somewhat striking in that the two studies were conducted concurrently using the same subject pool, identical stimulus tapes, and similar procedures. It is possible to explain this discrepancy by assuming that Ss expecting a recall test rehearsed more than
Ss expecting a recognition test (Atkinson \& Wickens, 1969) and, further, that Ss who rehearsed were more likely to rehearse own words and high-valued words than partner's words or low-valued words. Thus, differences due to value and assignment in the recall task may have been mediated by selective rehearsal, and the lack of these differences in the recognition task may reflect the relative absence of rehearsal. An alternative explanation for the lack of value and assignment differences in the recognition task is that $S s$ did indeed rehearse own and high-valued words but that the recognition test itself produced sufficient interference so that these rehearsed words were lost before Ss reached the critical stimulus cards; recall Ss could, however, immediately "dump out" rehearsed words currently held in short-term memory. If this last interpretation is correct, high-valued words that appear relatively early in the recognition deck should be better recognized than their low-valued counterparts, whereas no such differences should obtain later in the deck. An appropriate analysis was performed to check this hypothesis; however, no significant relationship between high-low value differences and deck position was obtained $(F=1.8)$.

Although assignment effects in the recall experiment were found for assigners of both sexes, the value effect was totally due to males, with female Ss showing a slight reverse pattern, despite the fact that payoff for high-valued words was 50 times greater than payoffs for low-valued words. The demonstrated inability of females to develop a simple strategy to maximize earnings could be related to sex of E; e.g., perhaps an opposite sex $E$ in this situation increases attention to the critical variables. 
This explanation is unlikely because E's role was minor and both tapes were recorded by a male voice. Alternatively, female insensitivity to these variables (overall females" scores were slightly higher than comparable male scores) could reflect cultural sex differences, i.e.. females are less responsive to incentives in experimental situations.

Assigners, whose role required them to announce money value and assignment, manifested greater value and assignment effects than did assignees. This suggests that these effects may depend on attending to and emphasizing the relevant variables through the active process of repeating aloud. In addition to this increased salience, assigners may have selected words to fit idiosyncratic mnemonic schemes which maximized recall of high-valued and own words, whereas assignees had no such opportunity.

\section{REFERENCES}

ATKINSON. R. C.. \& WICKENS. T. D. Human memory and the concept of reinforcement Technical Report 145, Institute for Mathematical Studies in the Social Sciences, Stanford Lniversity, 1969.

BJORK, R. A., LaBERGE, D., \& LEGRAND, R. The modification of short-term memory through instructions to forget. Psychonomic Science, 1968, 10, 55-56.

EAGLE. M., \& LEITER, E. Recall and recognition in intentional and incidental learning. Journal of Experimental Psychology. 1964. 68, 58-63.

GLUCKSBERG, S., \& KING, L. J. Motivated forgetting mediated by implicit verbal chaining: A laboratory analog of repression. Science, 1967, 158, 517-518.

GLUCKSBERG, S., \& ORNSTEIN, P. A. Reply to Weiner and Higgins: Motivated forgetting is not attributable to a confounding of original learning with retention. Journal of Verbal Learning \& Verbal Behavior, 1969. 8. 681-685.

PALERMO, D. S.. \& JENKINS. J. N. Word association norms: Grade school through college. Minneapolis: Lniversity of Minnesota Press. 1964

THORNDIKE. E. L.. \& LORGE. I. The teacher's word book of 30,000 words. New York: Burcau of Publications. Teachers College. Colımbia Lniversity, 1944.

WEINER. B. Effects of motivation on the availability and retrieval of memory traces. Psychological Bulletin, 1966.65.24-37.

WEINER. B.. \& HIGGINS. J. A mediational paradigm for the study of motivated forgetting: A critical analysis. Journal of Verbal Learning \& Verbal Behavior. 1969.8, $677-680$.

WFINER. B.. \& REED. H. Fffects of the instructional sets to remember and to forget on short-term retention. Journal of Experimental Psychology. 1969. 79. 226-232.

WINER. B. J. Statistical principles in experimental design. New York: McGraw-Hill, 1962.

\section{NOTES}

1. This research was partially supported by a grant from the Graduate School. Lniversity of Wisconsin. to the first author. Thank, are due to Luana Halm, Susan Miller, and Naney Olmstead for their assistance in running subjects, to William
Epstein and Paul Buckley for helpful comments. and to Jackie Guild for her "cooperation" as a pilot subject.

2. Neither the Bjork et al nor the Glucksberg and King methodology is subject to this criticism, but they both use less direct measures of voluntary forgetting than that of Weiner, and there is some debate about whether the Glucksberg and King paradigm actually taps voluntary forgetting (Weiner \& Higgens. 1969: Glucksberg \& Ornstein, 1969).

3. After the tirst recall test. Ss were instructed to write "any other words you recall regardless of assignment." A few words that should have appeared on the first test appeared on the second recall test. The words were counted as recalled even though Ss evidently had not coded assignment (own-other) correctly.

4. These stacks were used to construct a second recognition test, which was administered immediately after the first test.

5 . Low-valued words on the first tape and high-valued words on the second tape (the same words) were remembered better: this and higher order interactions involving the tape variable are most likely due to differences in item difficulty and will not be further considered. Assigners kept $50.5 \%$ of the 25 cent words and $49.5 \%$ of the $1 / 2$ cent words.

6. Separate analysis for assigners of each sex verifies the greater sensitivity of male Ss to the value and assignment manipulations. Males recalled more high-valued than low-valued words $[F(1,12)=14.56, p<.005]$, while females were unaffected by value $(\mathbf{F}<1)$. Both males $[F(1.12)=29.38, \quad p<.001]$ and females $[F(1.18)=8.23, p<.02]$ recalled more of their own words than their partner's words.

\section{Free vs unhibited recall}

WESTON A. BOLSFIELD, University of Connecticut, Storrs, Conn. 06268, and SUE R. ROSNER. Institute of Child Behavior and Development, University of Iowa, Iowa City, Iowa 52240

This study compared five multitrial free recalls of 20 minimally related words $u$ sing two instruction conditions: Condition S, standard free recall instructions; Condition $U$, uninhibited recall instructions in which $S$ s were told to emit all words occurring to them during recall. Errors were more prevalent for Condition $U$ and were predominately item repetitions. Although level of correct recall was similar for the two conditions on the first trial, Condition $U$ had significantly higher recall than Condition $S$ on the last test trial. This recall superionity was attributable to less intertrial forgetting under Condition $U$ and was independent of the amount of error production.

The present study describes an exploratory attempt to determine the degree of correspondence between covert and overt item recall in the multitrial free-recall (MTFR) task. It is well known that "errors," i.e., the emission of extralist items and intralist item repetitions, are relatively rare in MTFR. On the other hand, the organizational mechanisms of stimulus coding and response cueing (cf. Allen, 1968) involve the implicit use of extralist items for coding and item repetitions for response cueing. This discrepancy, between overt error production and the presumed occurrence of covert errors, may be due to the operation of a selector mechanism (Underwood \& Schulz, 1960, pp. 143-144) which serves selectively to filter correct from incorrect items during recall. One set of instructions used in the present study were, in effect, designed to release the inhibitory action of the selector mechanism. It was expected that these instructions would substantially increase the number of extralist intrusions and item repetitions in MTFR.

\section{METHOD}

The stimulus list comprised 20 minimally related words randomly selected from a 75-item list (Bousfield, Whitmarsh, \& Esterson, 1958). Each item, from five randomizations of the word list, was typed in capital letters on $3 \times 5$ in. index cards. A practice list of 10 printed numbers was similarly prepared. During input, Ss studied each of the stimulus items for $3 \mathrm{sec}$. The output trials allowed $80 \mathrm{sec}$ for oral recall, which was tape recorded. The following procedure was followed for each $S$ : practice instructions, one practice trial, instructions reread, five input-output trials with stimulus list

Introductory psychology undergraduates served as Ss. They were randomly assigned to two groups and were tested individually. Standard MTFR instructions were administered to the 13 Ss of the standard (S) condition. The following special statements were added to the usual MTFR instructions received by the $23 \mathrm{Ss}$ of the 